\title{
Antimicrobial activities of mycoleptodiscin B isolated from endophytic fungus Mycoleptodiscus sp. of Calamus thwaitesii Becc.
}

\author{
Ranga K. Dissanayake ${ }^{1}$, Pamoda B. Ratnaweera ${ }^{1,2.3}$, David E. Williams ${ }^{2}$, C. Dilrukshi Wijayarathne ${ }^{1}$, Ravi L. C. \\ Wijesundera ${ }^{4}$, Raymond J. Andersen ${ }^{2}$, E. Dilip de Silva ${ }^{1} *$ \\ ${ }^{1}$ Department of Chemistry, University of Colombo, Colombo 03, Sri Lanka. ${ }^{2}$ Departments of Chemistry and Earth, Ocean and Atmospheric Science, \\ University of British Columbia (UBC), Vancouver, Canada. ${ }^{3}$ Department of Science and Technology, Uva Wellassa University, Badulla, Sri Lanka. \\ ${ }^{4}$ Department of Plant Sciences, University of Colombo, Colombo 03, Sri Lanka.
}

\section{ARTICLE INFO \\ Article history: \\ Received on: 28/10/2015 \\ Revised on: 10/11/2015 \\ Accepted on: 11/12/2015 \\ Available online: $26 / 01 / 2016$}

\section{Key words:}

Mycoleptodiscus sp.,

Calamus thwaitesii,

mycoleptodiscin B,

endophytic fungus,

antimicrobial.

\begin{abstract}
Endophytic fungi are a promising source of novel biologically active compounds including antimicrobials. Plant endophytic fungi of Sri Lanka, an island with exceptionally high biodiversity and endemism, are a vastly untapped resource. Therefore this study was initiated with the objective of examining the antimicrobial producing potential of the endophytic fungi of Calamus thwaitesii Becc. from Sri Lanka. This examination resulted in the isolation of 21 fungi with 7 of them exhibiting antimicrobial properties. Further investigation of the Mycoleptodiscus sp. isolated from the leaves, which showed the best activity among them, resulted in the isolation of the known alkaloid mycoleptodiscin B and its structure was elucidated and confirmed by mass and nuclear magnetic resonance spectral data. Mycoleptodiscin B showed promising antimicrobial activity against Bacillus subtilis (MIC $0.5 \mu \mathrm{g} \mathrm{mL}^{-1}$ ) and Staphylococcus aureus (MIC $1 \mu \mathrm{g} \mathrm{mL}^{-1}$ ), and was less potent against methicillin resistant Staphylococcus aureus (MRSA, MIC $32 \mu \mathrm{g} \mathrm{mL}^{-1}$ ) and the pathogenic fungus Candida albicans (MIC $64 \mu \mathrm{g} \mathrm{mL}^{-1}$ ). This is the first study to report the isolation, identification and antimicrobial properties of endophytic fungi of $C$. thwaitesii and the antimicrobial activities of the alkaloid mycoleptodiscin B.
\end{abstract}

\section{INTRODUCTION}

Fungal endophytes colonize healthy tissues of host plants with no manifestations of disease symptoms and are an outstanding source of biologically active compounds with potential medicinal and agricultural applications (Aly et al., 2011). They are purportedly found in all plants occupying tropical and temperate climates to extreme arctic, alpine and xeric environments and their numbers are estimated to reach into millions of species (Zhang et al., 2006). Thus far only a very small percentage of endophytic fungi have been investigated for their secondary metabolite producing capacity and biological activities (Strobel and Daisy, 2003; Radic and Strukelj, 2012). Further perusal of the biosynthetic abilities of endophytic fungi, especially those occupying unique ecological niches, may lead to

\footnotetext{
* Corresponding Author

E. Dilip de Silva, Department of Chemistry, University of Colombo, Colombo 03, Sri Lanka.Email: dilip@chem.cmb.ac.lk
}

new molecular scaffolds useful as drug leads and result in more effective utilization of this resource.

Sri Lanka, a small island nation with a variety of climatic conditions exhibits high biodiversity with a remarkably high level of endemism among its flora (Myers et al., 2000; Mittermeier, 2005) that may harbor endophytes with distinctive biosynthetic abilities. In the backdrop that effective and innovative antibiotics are needed to combat drug resistant pathogenic bacteria, exploring the antibacterial producing capacity of such endophytes becomes meaningful. So far, only a few Sri Lankan plants have been systematically investigated for the production of antibacterial substances by their fungal endophytes. A recently initiated program to investigate the antimicrobial producing potential of endophytic fungi from distinct ecological settings of Sri Lanka has shown inspiring results justifying the continued research on this resource (Ratnaweera et al., 2014; Ratnaweera et al., 2015a \& b).

Calamus thwaitesii Becc. is a rattan, belonging to the family Palmae (Arecaceae) distributed in the Western Ghats of India and Sri Lanka (Sreekumar and Renuka, 2006). Due to over- 
exploitation for furniture industry $C$. thwaitesii is rapidly decreasing and in Sri Lanka it is listed as a vulnerable species, facing a high risk of extinction in the wild (MOE, 2012). The fungal endophytes of this plant or their bioactive metabolites have not been investigated previously. Herein we describe the isolation and identification of the endophytic fungi of $C$. thwaitesii and the antimicrobial activities of their laboratory cultures. The isolation, structure elucidation and antimicrobial activities of mycoleptodiscin B, a known alkaloid, from the endophyte Mycoleptodiscus sp. with the most promising activity are also described.

\section{MATERIALS AND METHODS}

\section{Isolation of the endophytic fungi from $C$. thwaitesii}

Healthy specimens of $C$. thwaitesii were collected from the village of Udugampola, in the Gampaha District, Sri Lanka in December 2013 and the identity of the plant was confirmed and authenticated by comparing with voucher specimens in the National Herbarium, Royal Botanical Gardens, Peradeniya, Sri Lanka. A voucher specimen (No. UOC/PTS/RD2014) of the plant used in the current investigation was deposited in the Department of Plant Sciences, University of Colombo, Sri Lanka.

Collected leaves and stems of $C$. thwaitesii were surface sterilized according to the protocol described in (Radji et al., 2011), within 5 hrs. of collection, and sterilized plant parts were dried, cut into small segments and placed on dilute malt yeast agar (dMYA) (HIMEDIA) dishes enriched with antibiotic (Chloramphenicol $50 \mathrm{mg} / \mathrm{L}$ ) under aseptic conditions and incubated at room temperature for several days. The endophytic fungi emerging from the edges of the plant segments were repeatedly sub-cultured on antibiotic absent sterile potato dextrose agar (PDA) dishes until pure cultures were obtained.

\section{Identification of the endophytic fungi}

The isolated endophytic fungi were initially identified through colony morphological features and by microscopic (OLYMPUS-CX21FS1) examination of hyphae and reproductive structures using slide cultures. The identities were confirmed by using molecular biological techniques. For this, first the fungal DNA was extracted from the mycelia using a published protocol (Kariyawasam et al., 2012). The target ITS region including the 5.8S gene, was amplified by polymerase chain reaction (PCR) using universal primers ITS 1 and ITS 4 under the conditions, initial denaturation of $5 \mathrm{~min}$. at $94{ }^{\circ} \mathrm{C}$, followed by 35 cycles of 30 sec. at $94{ }^{\circ} \mathrm{C}, 1 \mathrm{~min}$ at $55{ }^{\circ} \mathrm{C}$ and $2 \mathrm{~min}$ at $72{ }^{\circ} \mathrm{C}$, with a final extension of 7 min. at $72{ }^{\circ} \mathrm{C}$ (Diaz et al., 2012).

Amplified DNA was sequenced commercially and was analyzed by BLAST [National Center for Biotechnology Information (NCBI)] and accession numbers were obtained for the gene sequences. The fungal voucher specimens were preserved on PDA slants at $4{ }^{\circ} \mathrm{C}$ at the Pathology Laboratory, Department of Plant Sciences, University of Colombo, Sri Lanka.

\section{Fermentation, extraction and antimicrobial activity}

Each isolated endophytic fungus was grown separately on six PDA dishes and incubated for 2-5 weeks. When the fungi reached the sporulation stage, each fungus together with the culture medium was cut into small pieces and immersed in $200 \mathrm{~mL}$ of ethyl acetate (EtOAc) for $24 \mathrm{~h}$, the resulting extracts were filtered and the filtrates were evaporated to dryness under reduced pressure (BUCHI-R-200 rotary evaporator). The resulting fungal extracts were tested, in triplicate against four pathogenic bacteria, Staphylococcus aureus (ATCC 25923), Bacillus cereus (ATCC 11778), Pseudomonas aeruginosa (ATCC 9027) and Escherichia coli (ATCC 35218) at 300 and $50 \mu \mathrm{g} /$ disc concentrations using standard agar disc diffusion assay. [positive control - Gentamycin (20 $\mu \mathrm{g} / \mathrm{disc})$; negative control - methanol]. After incubation overnight, the mean diameter of the inhibition zones were recorded. The anti-fungal bio assays of crude fungal extracts were performed using the disc diffusion method against Fusarium oxysporum, Rigidoporus microporus, Colletotrichum gloeosporioides, and Aspergillus niger at $300 \mu \mathrm{g} / \mathrm{disc}$. (Positive control - a 1:1 A mixture of Ketoconazole and Itraconazole (10 $\mu \mathrm{g} / \mathrm{disc})$ ) The growth inhibitions were visually examined by comparing with the positive control.

Fungal strain (RDWW-02) which showed the best antimicrobial activity was grown in large scale, on sterile PDA in 400 Petri dishes (size, $100 \times 120 \mathrm{~mm}$ ) and was incubated for 14 days at $28{ }^{\circ} \mathrm{C}$. Next, this large scale fungal culture was extracted thrice with EtOAc $(3 \times 2.5 \mathrm{~L})$. The combined extracts were filtered and were concentrated in vacuo. This EtOAc extract was tested for antimicrobial activity against the two Gram-positive bacteria, Staphylococcus aureus and Bacillus cereus at $50 \mu \mathrm{g} / \mathrm{disc}$ concentration using the agar disc diffusion method, to confirm the activity before proceed to the next step.

\section{Isolation of Mycoleptodiscin B}

The EtOAc extract $(400 \mathrm{mg})$ of the fungal strain RDWW-02 was first subjected to solvent/solvent partitioning between hexane and $\mathrm{MeOH} / \mathrm{H}_{2} \mathrm{O}, 8: 2(500 \mathrm{~mL}$ each) and after the separation of the hexane layer, the polarity of the aqueous layer was increased to $\mathrm{MeOH} / \mathrm{H}_{2} \mathrm{O}, 6: 4$ by the addition of $\mathrm{H}_{2} \mathrm{O}$ and extracted with $\mathrm{CHCl}_{3}(500 \mathrm{~mL})$. The $\mathrm{CHCl}_{3}$ layer was separated and the aqueous layer was concentrated at reduced pressure and was partitioned between $\mathrm{H}_{2} \mathrm{O}$ and EtOAc. Next the $\mathrm{CHCl}_{3}$ soluble fraction $(130 \mathrm{mg})$ which retained the antimicrobial activity was further purified using normal phase silica column chromatography $(2 \times 25 \mathrm{~cm})$ using gradient elution (starting with hexane, then mixtures of hexane/EtOAc to EtOAc). The resulting active fraction $(58 \mathrm{mg}$ ) was again purified by normal phase silica column chromatography $(1.5 \times 35 \mathrm{~cm})$ with gradient elution (hexane/EtOAc, 4:1 to hexane/EtOAc, 1:9). The resulting active fraction was next subjected to size-exclusion chromatography (Sephadex LH 20; $1.5 \times 60 \mathrm{~cm}$ with methanol) and finally purified by $\mathrm{C}_{18}$ reversed-phase HPLC using a CSC-Inertisil 150A/ODS2, 5 $\mu \mathrm{m} 25 \times 0.94 \mathrm{~cm}$ column with $4: 1 \mathrm{MeCN} / \mathrm{H}_{2} \mathrm{O}$ as eluent with a flow rate of $2 \mathrm{~mL} \mathrm{~min}^{-1}$ to yield mycoleptodiscin $\mathrm{B}$. 


\section{Structure elucidation of Mycoleptodiscin B}

The structure elucidation of mycoleptodiscin B, was done using nuclear magnetic resonance (NMR) and mass spectral data. ${ }^{1} \mathrm{H},{ }^{13} \mathrm{C}$ and $2 \mathrm{D}$ NMR spectral data sets in DMSO- $d_{6}$ were obtained using a Bruker AV-600 spectrometer with a $5 \mathrm{~mm}$ CPTCI cryoprobe, while low and high resolution ESI-QIT-MS were recorded on a Bruker-Hewlett Packard 1100 Esquire-LC system mass spectrometer.

\section{Antimicrobial activity of Mycoleptodiscin B}

Mycoleptodiscin B was assayed for antimicrobial activity against three Gram-positive bacteria, B. subtilis (UBC 344), S. aureus (ATCC 43300) and methicillin resistant $S$. aureus (MRSA, ATCC 33591), two Gram-negative bacteria, E. coli (UBC 8161), $P$. aeruginosa (ATCC 27853) and the pathogenic fungus C. albicans (ATCC 90028). The minimum inhibitory concentrations (MICs) were determined using broth micro-dilution method according to National Committee for Clinical Laboratory Standards with modification using Mueller Hinton broth as the medium (NCCLS, 2002). The MIC end point was taken as the lowest concentration with more than $90 \%$ growth inhibition. Optical density of the microbial growth was determined (at 600 nm) using a DTX 880 (Beckman Coulter Inc.) plate reader. The commercial antimicrobial agents polymyxin B for B. subtilis, E. coli and $P$. aeruginosa, rifamycin for $S$. aureus and MRSA and amphotericin for $C$. albicans were used as positive controls (Concentration series used: 2.0-0.004 $\mu \mathrm{g} \mathrm{mL}^{-1}$ ).

\section{RESULTS AND DISCUSSION}

\section{Isolation and identification of the endophytic fungi}

A total of 21 morphologically distinct endophytic fungi, 12 from leaves and nine from stems were isolated. The identities, accession numbers and incubation periods are given in Table 1. The endophytic fungi isolated belonged to 13 genera with each genus Colletotrichum, Curvularia, Phomopsis and Aspergillus represented by four, three, three, and two species respectively and the rest of the genera present as a single species. These fungi belong to three Ascomycota classes. The Aspergillus species belong to Eurotiomycetes, while Curvularia, Lasiodiplodia, Dendryphiella, Setosphaeria, Bipolaris, Macrophomina species belong to Dothideomycetes and Mycoleptodiscus, Phomopsis, Diaporthe, Calonectria, Fusarium, Colletotrichum species belong to Sordariomycetes class. Most of these genera including Colletotrichum, Curvularia, Phomopsis, Aspergillus and Fusarium are common as plant pathogenic fungi though non-pathogenic endophytic forms of these also exist (Strange and Scott, 2005; Yeasmin and Shamsi, 2013). Some reports have stated that endophytes remain latent, with symptomless nature inside the host plant only until the environmental conditions are favourable for the fungus to turn into aggressive saprophytes or opportunistic pathogens (Sieber, 2007; Rodriguez and Redman, 2008). The fungi in the current study were isolated from a healthy, symptomless plant after thorough surface sterilization, which confirm the isolated fungi were in the endophytic form during the isolation period.

\section{Antimicrobial activity of the crude endophytic fungal extracts}

The mean diameter ( \pm Standard error $(\mathrm{SE})$ ) of the inhibition zones of the active crude fungal extracts in the antimicrobial bioassays are shown in Table 2. None of the extracts were active against the two Gram negative bacteria tested, while seven fungal extracts inhibited the growth of at least one Gram positive bacterial strains at $300 \mu \mathrm{g} /$ disc. As suggested by (Hugo, 1998), this may be due to the rigid and complex cell wall structures in Gram negative bacteria. Among them RDWW-12 and RDWW-16 were only active against $S$. aureus and other five extracts were active against both $S$. aureus and B. cereus. Only RDWW-02, Mycoleptodiscus sp., showed antibacterial activity against Gram positive bacteria at $50 \mu \mathrm{g} /$ disc concentration,

Table 1: Identities of isolated endophytic fungi with their origin, incubation period, and accession numbers.

\begin{tabular}{|c|c|c|c|c|}
\hline Endophytic fungal strain & Isolated plant section & Incubation period & Identity of the endophytic fungus & Accession number \\
\hline RDWW-01 & leaves & 18 days & Calonectria pteridis & KR 092388 \\
\hline RDWW-02 & leaves & 14 days & Mycoleptodiscus $\mathrm{sp}$. & KP 119836 \\
\hline RDWW-03 & stem & 7 days & Colletotrichum gigasporum & KR 092389 \\
\hline RDWW-04 & leaves & 14 days & Bipolaris sp. & KR 092390 \\
\hline RDWW-05 & leaves & 7 days & Aspergillus fumigatus & KR 092391 \\
\hline RDWW-06 & stem & 7 days & Curvularia geniculata & KT 150263 \\
\hline RDWW-07 & leaves & 10 days & Lasiodiplodia theobromae & KR 092392 \\
\hline RDWW-08 & stem & 18 days & Colletotrichum horii & KT 150264 \\
\hline RDWW-09 & stem & 18 days & Curvularia sp. & KT 150265 \\
\hline RDWW-10 & stem & 21 days & Diaporthe sp. & KT 150266 \\
\hline RDWW-11 & stem & 7 days & Colletotrichum gloeosporioides & KT 150267 \\
\hline RDWW-12 & stem & 18 days & Dendriphiella sp. & KT 150268 \\
\hline RDWW-14 & leaves & 14 days & Phomopsis sp. & KT 150270 \\
\hline RDWW-15 & leaves & 21 days & Aspergillus terreus & KT 150271 \\
\hline RDWW-16 & leaves & 7 days & Macrophomina phaseolina & KT 150272 \\
\hline RDWW-17 & stem & 7 days & Colletotrichum sp. & KT 150273 \\
\hline RDWW-18 & leaves & 7 days & Curvularia sp. & KT 150274 \\
\hline RDWW-19 & leaves & 18 days & Fusarium solani & KT 150275 \\
\hline RDWW-21 & leaves & 18 days & Phomopsis sp. & KT 150277 \\
\hline RDWW-23 & leaves & 7 days & Phomopsis sp. & KT 150279 \\
\hline RDWW-24 & stem & 7 days & Setosphaeria rostrata & KT 150280 \\
\hline
\end{tabular}


Table 2: Antimicrobial activity of the crude extracts of endophytic fungi of the plant $C$. thwaitesii.

\begin{tabular}{|c|c|c|c|c|c|c|}
\hline \multirow{3}{*}{$\begin{array}{l}\text { Endophytic fungal } \\
\text { strain }\end{array}$} & \multicolumn{4}{|c|}{$\begin{array}{c}\text { Antibacterial activity } \\
\text { Mean diameter of the inhibition zone }(\mathrm{mm}) \pm \mathrm{SE}\end{array}$} & \multicolumn{2}{|c|}{$\begin{array}{c}\text { Antifungal activity } \\
300 \mu \mathrm{g} / \text { disc }\end{array}$} \\
\hline & \multicolumn{2}{|c|}{ S. aureus } & \multicolumn{2}{|c|}{ B. cereus } & \multirow{2}{*}{ F. oxysporum } & \multirow{2}{*}{ R. microporus } \\
\hline & $300 \mu \mathrm{g} / \mathrm{disc}$ & $50 \mu \mathrm{g} / \mathrm{disc}$ & $300 \mu \mathrm{g} / \mathrm{disc}$ & $50 \mu \mathrm{g} / \mathrm{disc}$ & & \\
\hline RDWW-01 & $07.0 \pm 0.2$ & - & $09.0 \pm 0.3$ & - & - & - \\
\hline RDWW-02 & $22.4 \pm 1.3$ & $13.2 \pm 0.5$ & $16.3 \pm 0.6$ & $10.1 \pm 0.2$ & + & + \\
\hline RDWW-07 & $10.3 \pm 0.1$ & - & $12.2 \pm 0.5$ & - & - & - \\
\hline RDWW-12 & $12.1 \pm 0.3$ & - & - & - & - & - \\
\hline RDWW-14 & $13.0 \pm 0.6$ & - & $09.0 \pm 0.4$ & - & - & - \\
\hline RDWW-15 & $09.4 \pm 0.2$ & - & $09.6 \pm 0.4$ & - & + & + \\
\hline RDWW-16 & $11.9 \pm 0.4$ & - & - & - & - & - \\
\hline+ Ve control & $23.1 \pm 1.0$ & $21.7 \pm 0.9$ & $20.6 \pm 0.8$ & $22.3 \pm 0.8$ & +++ & +++ \\
\hline -Ve control & - & - & - & - & - & - \\
\hline
\end{tabular}

+ growth inhibition of the fungus

thus this was selected for the isolation of bioactive metabolites. The genus Mycoleptodiscus is known as a plant-associated fungus and has previously been isolated from Desmotes incomparabilis (Rutaceae) in Panama and from the medicinal plant Tinospora crispa (Menispermaceae) in Thailand as endophytes (Ortega et al., 2013; Siriwach et al., 2012).

Only two crude extracts, RDWW-02 and RDWW-15, out of 21 , exhibited antifungal activity against $F$. oxysporum, $R$. microporus (Table 2). None of the extracts were active against $C$. gloeosporioides and A. niger. The two extracts that showed antifungal activity also showed activity against Gram positive bacteria. Although antifungal activities of plant endophytic fungi have been reported (Fisher, 1984; Liu et al., 2001), antifungal activities of plant endophytic fungi are not as common as antibacterial activities (Hugo, 1998).

\section{Isolation and structure elucidation of the bioactive metabolite of the Mycoleptodiscus sp.}

The bioassay guided fractionation of the EtOAc extract of RDWW-02 led to the isolation of the active compound ( $2 \mathrm{mg}$ ) as a reddish orange amorphous solid eluting at a retention time of 16 minutes under the HPLC conditions used. This compound gave a $[\mathrm{M}+\mathrm{Na}]^{+}$ion in the HRESIMS at $\mathrm{m} / \mathrm{z} 390.2023$ appropriate for the molecular formula of $\mathrm{C}_{23} \mathrm{H}_{29} \mathrm{NO}_{3}$. Analysis of ${ }^{1} \mathrm{H}$ and ${ }^{13} \mathrm{C}$ NMR data as well as 2D NMR (COSY, HSQC, HMBC, tROESY) spectral data in DMSO- $d_{6}$ revealed that the structure of the active compound matches that of the known alkaloid mycoleptodiscin B (Fig. 1). A comparison of ${ }^{13} \mathrm{C}$ values obtained for mycoleptodiscin

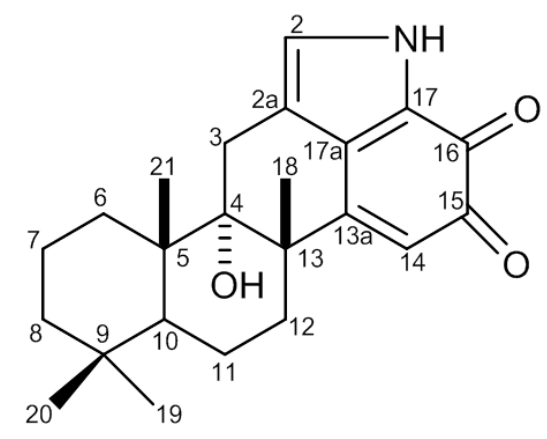

Fig. 1: Chemical structure of the alkaloid, mycoleptodiscin B.
$\mathrm{B}$ in the present study and published data are given in Table 3 (Ortega et al., 2013). The ${ }^{1} \mathrm{H}$ NMR (DMSO- $d_{6}$ ) values obtained in the present study and their assignments are: $\delta 12.4(\mathrm{NH}, \mathrm{s}), \delta$ 7.13(H-2, s), $\delta 5.56(\mathrm{H}-14, \mathrm{~s}), \delta 4.14(\mathrm{OH}, \mathrm{s}), \delta 2.87\left(\mathrm{H}-3_{\mathrm{ax}}, \mathrm{d}, 16.4\right.$ $\mathrm{Hz}), \delta 2.52\left(\mathrm{H}-3_{\mathrm{eq}}, \mathrm{d}, 16.4 \mathrm{~Hz}\right), \delta 1.84\left(\mathrm{H}-12_{\mathrm{ax}}, \mathrm{dt}, 12.8,4.0 \mathrm{~Hz}\right), \delta$ $1.72\left(\mathrm{H}-12_{\text {eq }}, \mathrm{td}, 12.8,5.6 \mathrm{~Hz}\right), \delta 1.69(\mathrm{H}-10, \mathrm{dd}, 12.5,2.1 \mathrm{~Hz}), \delta$ $1.57\left(\mathrm{H}_{2}-11, \mathrm{~m}\right), \delta 1.51\left(\mathrm{H}-6_{\mathrm{ax}}, \mathrm{m}\right), \delta 1.40\left(\mathrm{H}_{2}-7, \mathrm{~m}\right), \delta 1.30$ $\left(\mathrm{H}-8_{\text {eq }}, \mathrm{m}\right), \delta 1.25\left(\mathrm{H}-6_{\mathrm{eq}}, \mathrm{m}\right), \delta 1.22\left(\mathrm{H}_{3}-18, \mathrm{~s}\right), \delta 1.09\left(\mathrm{H}_{3}-21, \mathrm{~s}\right), \delta$ $1.05\left(\mathrm{H}-8_{\mathrm{ax}}, \mathrm{dt}, 13.6,3.5 \mathrm{~Hz}\right), \delta 0.87\left(\mathrm{H}_{3}-19, \mathrm{~s}\right), \delta 0.84\left(\mathrm{H}_{3}-20, \mathrm{~s}\right)$.

\section{Antimicrobial activity of mycoleptodiscin B}

Mycoleptodiscin B showed strong selective antibacterial activities against Gram-positive B. subtilits (UBC 344), and S. aureus (ATCC 43300) with MIC values of 0.5 and $1 \mu \mathrm{g} \mathrm{mL}^{-1}$ respectively (Table 4). It is less active against MRSA (ATCC 33591) and the pathogenic fungus C. albicans (ATCC 90028) and inactive against the Gram negative bacteria E. coli (UBC 8161) and $P$. aeruginosa (ATCC 27853) (Table 4). This is the first report of the antimicrobial activities of mycoleptodiscin B.

Mycoleptodiscin B, together with mycoleptodiscin A, has previously been isolated from the Mycoleptodiscus species endophytic in D. incomparabilis collected in Panama. In that study mycoleptodiscin B is reported to possess moderate cytotoxic effects against four cancer cell lines (H460, A2058, H522-T1 and PC-3) with $\mathrm{IC}_{50}$ values ranging from 0.60 to $0.78 \mu \mathrm{M}$ (Ortega et al., 2013). The present study is the first to report the antimicrobial activities of the alkaloid Mycoleptodiscin B. Additionally, a new chromone derivative, mycoleptione has been isolated from the Mycoletodiscus species endophytic in T. crispa (Siriwach et al., 2012).

The stem sap of $C$. thwaitesii is reported to be used as an antifertility drug (Bhandary et al., 1995). However, there are no reports of any antibacterial activity attributed to this plant. Harboring endophytes which are capable of producing potent antimicrobial substances such as mycoleptodiscin B may be a valuable adaptation of hosts, which are unable to biosynthesize antibacterial substances on their own, to thwart potentially damaging microbial attacks. 
Table 3: Comparison of ${ }^{13} \mathrm{C}$ NMR data of mycoleptodiscin B from the present study (in DMSO- $\left.d_{6}\right)$ with published data (in $\left.\mathrm{CD}_{3} \mathrm{OD}\right)(\mathrm{Ortega}$ et al., 2013).

\begin{tabular}{|c|c|c|c|c|c|}
\hline \multirow[t]{2}{*}{$\mathrm{C \#}$} & \multicolumn{2}{|c|}{${ }^{13} \mathrm{C} \delta(\mathrm{ppm})$ for mycoleptodiscin B } & \multirow[t]{2}{*}{ C\# } & \multicolumn{2}{|c|}{${ }^{13} \mathrm{C} \delta(\mathrm{ppm})$ for mycoleptodiscin B } \\
\hline & Present study & Published values & & Present study & Published values \\
\hline 2 & 128.5 & 130.1 & 13 & 43.6 & 45.4 \\
\hline $2 \mathrm{a}$ & 119.8 & 121.6 & $13 \mathrm{a}$ & 164.3 & 166.2 \\
\hline 3 & 24.5 & 25.8 & 14 & 114.6 & 116.4 \\
\hline 4 & 80.2 & 82.5 & 15 & 166.2 & 167.7 \\
\hline 5 & 42.7 & 44.5 & 16 & 185.1 & 187.1 \\
\hline 6 & 31.6 & 33.3 & 17 & 124.6 & 126.0 \\
\hline 7 & 17.9 & 19.4 & $17 \mathrm{a}$ & 130.2 & 132.6 \\
\hline 8 & 41.1 & 42.7 & 18 & 24.5 & 25.5 \\
\hline 9 & 32.8 & 34.2 & 19 & 33.5 & 34.1 \\
\hline 10 & 45.2 & 47.3 & 20 & 21.5 & 22.1 \\
\hline 11 & 17.7 & 19.3 & 21 & 17.6 & 18.6 \\
\hline 12 & 30.8 & 32.6 & & & \\
\hline
\end{tabular}

Table 4: MIC values obtained for mycoleptodiscin B and the positive controls.

\begin{tabular}{|c|c|c|c|c|c|c|}
\hline & \multicolumn{6}{|c|}{ MIC values $\left(\mu \mathrm{g} \mathrm{mL}^{-1}\right)$} \\
\hline & B. subtilis & S. aureus & MRSA & E. coli & P. aeruginosa & C. albicans \\
\hline Mycoleptodiscin B & 0.5 & 1 & 32 & $>64$ & $>64$ & 64 \\
\hline Polymixin B & 8 & - & - & 4 & 4 & - \\
\hline Rifamycin & - & 0.015 & 0.015 & - & - & - \\
\hline Amphotericin & - & - & - & - & - & 0.062 \\
\hline
\end{tabular}

\section{CONCLUSION}

This study revealed that Calamus thwaitesii harbors many fungi capable of producing antimicrobial substances active especially against Gram positive bacteria, and thus is a potentially valuable resource for the isolation of novel antimicrobial compounds. Bioassay guided fractionation of the organic extract of Mycoleptodiscus sp. led to the isolation of the alkaloid mycoleptodiscin B, with potent and selective antimicrobial activity.

\section{CONFLICT OF INTEREST STATEMENT}

Authors declare that they have no conflict of interest

\section{ACKNOWLEDGEMENTS}

Financial support was by the National Science Foundation (NSF) of Sri Lanka, Grant RG/2012/NRB/01 to EDdeS and by the National Sciences and Engineering Research Council (NSERC) to RJA.

\section{REFERENCES}

Aly AH, Debbab A, Proksch P. Fungal endophytes: unique plant inhabitants with great promises. Appl J Microbiol Biotechnol, 2011; 90:1829-1845.

Bhandary MJ, Chandrashekar KR, Kaveriappa KM. Medical ethnobotany of the Siddis of Uttara Kannada district, Karnataka, India. J Ethnopharmacol, 1995; 47:149-158.

Diaz PL, Hennell JR, Sucher NJ. 2012. Genomic DNA extraction and barcoding of endophytic fungi. In: Sucher NJ, Hennell JR, Carles MC, eds. Plant DNA Fingerprinting and Barcoding: Methods and Protocols, Methods in Molecular Biology, Springer Science+Buisness Media, 862:171-179.

Fisher PJ, Anson AE, Petrini O. Antibiotic activity of some endophytic fungi from ericaceous plants. Bot Helv, 1984; 94:249-253.

Hugo WB. 1998. Bacteria. In: Hugo WB, Russell AD. eds. Pharmaceutical Microbiology, sixth edition. blackwell Science Ltd, United Kingdom, pp. 4-8.
Kariyawasam GK, Mithrasen YJPK, Fernando THPS, Wijesundera RLC, Wijesundera WSS. 2012. A new cost effective method for extracting genomic DNA from fungi. Abstracts of papers, 5th Annual sessions, Institute of Biochemistry Molecular Biology and Biotechnology, Colombo; 2012 April 27. Colombo: Institute of Biochemistry, Molecular Biology and Biotechnology; 5:49.

Liu CH, Zou WX, Lu H, Tan RX. Antifungal activity of Artemisia апnиa endophyte cultures against phytopathogenic fungi. J Biotechnol, 2001; 88:277-282.

Mittermeier RA, Gil RP, Hoffman M, Pilgrim J, Brooks T, Mittermeier CG, Lamoreux J, Fonseca GAB. 2005. Hotspots revisited: Earth's biologically richest and most endangered terrestrial eco-regions. Boston: University of Chicago Press, USA.

MOE. 2012. The National Red List 2012 of Sri Lanka; Conservation Status of the Fauna and Flora. Ministry of Environment, Colombo, viii+476pp.

Myers N, Mittermeier RA, Mittermeier CG, Gustavo A, da Fonseca B, Kent J. Biodiversity hotspots for conservation priorities. Nature, 2000; 403:853-858.

National Committee for Clinical Laboratory Standards (NCCLS). 2002. Performance standards for antimicrobial susceptibility tests, Approved Standard, document M2-A8. 8th ed. Wayne (PA).

Ortega HE, Graupner PR, Asai Y, TenDyke K, Qiu D, Shen YY, Rios N, Arnold AE, Coley PD, Kursar TA, Gerwick WH, CubillaRios L. Mycoleptodiscins A and B, cytotoxic alkaloids from the endophytic fungus Mycoleptodiscus sp. F0194. J Nat Prod, 2013; 76:741744.

Radic N, Strukelj B. Endophytic fungi-The treasure chest of antibacterial substances. Phytomedicine, 2012; 19:1270-1284.

Radji M, Sumiati A, Rachmayani R, Elya B. Isolation of fungal endophytes from Garcinia mangostana and their antibacterial activity. Afr J Biotechnol, 2011; 10:103-107.

Ratnaweera PB, Williams DE, de Silva ED, Wijesundera RLC, Dalisay DS, Andersen RJ. Helvolic acid, an antibacterial nortriterpenoid from a fungal endophyte Xylaria sp. of orchid Anoectochilus setaceus endemic to Sri Lanka. Mycology: Int J Fun Biol, 2014; 5:23-28.

Ratnaweera PB, Williams DE, Patrick BO, de Silva ED, Andersen RJ. Solanioic acid, an antibacterial degraded steroid produced in culture by the fungus Rhizoctonia solani isolated from tubers of the medicinal plant Cyperus rotundus. Org Lett, 2015a; 17:2074-2077.

Ratnaweera PB, de Silva ED, Williams DE, Andersen RJ. Antimicrobial activities of endophytic fungi obtained from the arid zone invasive plant Opuntia dillenii and the isolation of equisetin, from endophytic Fusarium sp. BMC Complem Altern M, 2015b; 15:220. 
Rodriguez R, Redman R. More than 400 million years of evolution and some plants still can't make it on their own: Plant stress tolerance via fungal symbiosis. J Exp Bot, 2008; 59:1109-1114.

Sieber TN. Endophytic fungi in forest trees: are they mutualists? Fungal Biol Rev, 2007; 21:75-89.

Siriwach R, Kinoshita H, Kitani S, Igarashi Y, Pansuksan K, Panbangred W, Nihira T. Mycoleptione, a new chromone derivative isolated from the endophytic fungus Mycoleptodiscus sp. MU41. J Antibiot, 2012; 65:627-629.

Sreekumar VB, Renuka C. Assessment of genetic diversity in Calamus thwaitesii Becc. (Arecaceae) using RAPD markers. Biochem Syst Ecol, 2006; 34:397-405.

Strange RN, Scott PR. Plant disease: A threat to global food security. Annu Rev Phytopathol, 2005; 43:83-116.

Strobel GA, Daisy B. Bioprospecting for microbial endophytes and their natural products. Microbiol Mol Biol R, 2003; 67:491-502.
Yeasmin F, Shamsi S. Phylloplane mycoflora of Gerbera spp. and their pathogenic potentiality. J Bangladesh Aca Sci, 2013; $37: 211-217$

Zhang HW, Song YC, Tan RX. Biology and Chemistry of endophytes. Nat Prod Rep, 2006; 23:753-771.

\section{How to cite this article:}

Dissanayake RK, Ratnaweera PB, Williams DE, Wijayarathne CD, Wijesundera RLC, Andersen RJ, deSilva ED. Antimicrobial activities of mycoleptodiscin B isolated from endophytic fungus Mycoleptodiscus sp. of Calamus thwaitesii Becc. J App Pharm Sci, 2016; 6 (01): 001-006. 